\title{
Enhancing Managers' Leadership Capabilities with a Leadership Process Reference Model
}

\begin{abstract}
Geographically dispersed integrated project teams collaborating in virtual environments face many challenges in the successful completion of projects, particularly when the project teams are non-homogenous. Model-based process improvement provides a viable way for organizations to improve the capability of software development teams, including the effectiveness of leaders in charge of integrated teams operating in virtual environments. Evolving a Process Reference Model (PRM) covering this activity has therefore been the subject of an on-going research project at Griffith University. The outcomes of this project may prove useful as a means to improving leadership capability, particularly in relation to complex, multidisciplinary teamed projects conducted in virtual environments. This paper introduces the nature and scope of the Process Reference Model and presents the preliminary findings of the validation phase of the PRM development.
\end{abstract}

Keywords: process, process model, sociotechnical, organisational behaviour, leadership, management.

\section{Introduction}

Leadership is the art of getting someone else to do something you want done because he wants to do it. Dwight D. Eisenhower [1]. Of the hundreds of quotes about leadership from all walks of life and periods, this quote from a former U.S. President and wartime leader seems to exhibit best, though perhaps not explain, the enduring enigma that is leadership. A manager may use authority to achieve compliance, but a leader finds a way to make the person want to do it.

Leadership has been observed and studied for countless generations, yet interestingly little consensus exists as to what true leadership is. Intense and on-going controversy exists between psychologists, sociologists, historians, political scientists and management researchers on this point. According to Yukl, No universally accepted definition of leadership has yet been developed. [2]. After thousands of empirical studies performed on leadership over the previous 75 years, no clear and unequivocal understanding has emerged as to how we can distinguish leaders from non-leaders [3].

Conventional wisdom maintains that leadership is an innate ability that natural leaders are born with, and which cannot be effectively learned. Another school of thought, typified by Warren Bennis [4] and Peter Drucker, [5] maintains that leadership can indeed be learned; that in effect, leaders are made rather than born. This is an underlying assumption of this project, a view supported by Plato who maintained in The Republic that the art of ruling (leadership) can be based on scientific principles -it can be learned [6]. The leader (ruler) uses the dialectic method to rationally analyse situations to determine appropriate courses of action with wisdom and understanding. Analysis is applied to produce improvement; Plato's method is seen to be compatible with the spirit and practice of process improvement. 
Meanwhile in the world of technology development, the business of managing complex projects across a variety of disciplines and geographical locations has never been more difficult, given the rising complexity of a global economic environment and the multi-national corporate entities that now inhabit this new world. There would appear to be a clear need to find improved ways of managing this often difficult process.

Accordingly, after a broad review of the literature on leadership generally, and on leadership of virtual and integrated teams, the material has been synthesized into a Process Reference Model (PRM) for leadership using the requirements specified in ISO/IEC 15504-2:2004.

The PRM is currently being subjected to verification in a series of Design Research iterations in which the existence of objective evidence is determined to support the purpose and outcomes of the processes within the PRM.

Can leadership be adequately described in a Process Reference Model? A fundamental assumption of this project is that leadership can in fact be adequately described in a process model.

Repenning and Sterman [7] observe a broad movement among "managers, consultants and scholars" to recognize the value of understanding an organizations activities in terms of processes rather than functions. While this tends to confirm the effectiveness of defined processes to solve the various challenges facing organizations, it considers also the limitations, namely the significantly high failure rate of process improvement exercises.

Given this recognition of the efficacy of process, there is no observable reason from Repenning and Sterman [7] to suggest that process modeling could not be applied to leadership. Indeed, Total Quality Management (TQM) emphasises the importance of leadership (along with human resource issues and strategic planning) to achieving success with TQM.

Watts Humphrey [8] demonstrated the importance of leadership in the software development domain, including the importance of managers to learn leadership skills in Winning with Software. Humphrey notes that as Director of programming with IBM he supervised 4,000 software professionals across many locations. His first step transforming this extended team from one which had never delivered anything on time to one that did not miss a single commitment was to send 1,000 managers on a one week training course to establish effective management and engineering practices [8].

Commitment to defined process in the software development domain, as typified by Humphrey [8] is reflected more broadly by W. Edwards Deming who is famously quoted as saying "If you can't describe what you are doing as a process, you don't know what you're doing." [9]. If we accept the basic proposition that leadership can be learned rather than only be had through inheritance, then theoretically it can be described as a process, as suggested by Deming. 


\section{Evolution of the Leadership Model}

The conceptual model acknowledges the basic distinction between co-located and virtual teams, and the fact that integrated teams can be either. Virtual teams do not have to be integrated but commonly are. Likewise, integrated teams do not have to be distributed, but commonly are. Therefore, the characteristics of successful teams and successful leaders are considered for both co-located and virtual teams, culminating in the characteristics of successful leaders of integrated teams operating in virtual environments. The end of this process of review and synthesis would be a process assessment model (PAM) for successful leaders of integrated teams operating in virtual environments.

The figure below illustrates the evolution of the leadership model.

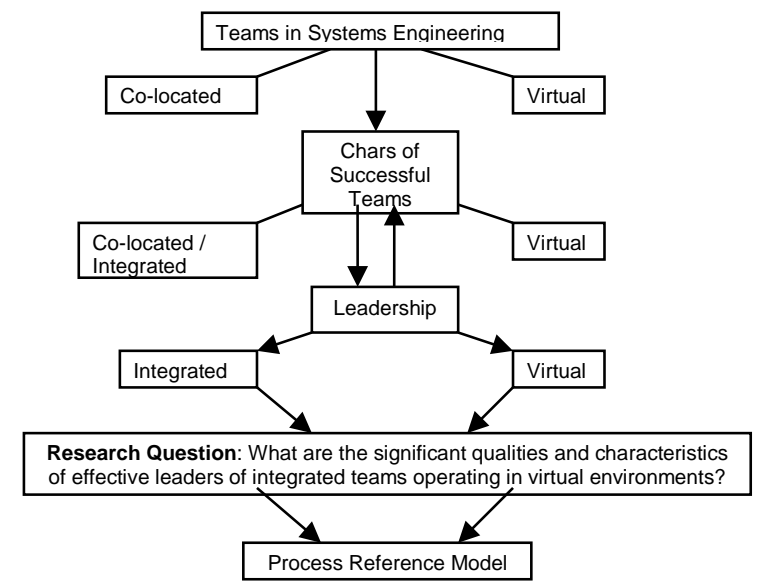

Figure 1: Conceptual overview

\section{Using Design Research to Develop the Process Reference Model \& Assessment Model}

Design Research focuses on the development and performance of (designed) artefacts with the explicit intention of improving the functional performance of the artefact. In this broad sense, the domain of software development process improvement (using Model-based Process Improvement) is one kind of artefact whose improvement is facilitated by the design research approach. Design research is typically applied to categories of artefact including (but not limited to) algorithms, human/computer interfaces, design methodologies (including process models) and languages. Its application is most notable in the Engineering and Computer Science disciplines, though is not restricted to these and can be found in many disciplines and fields [10]. Such renowned research institutions as MIT's Media Lab, Stanford's Centre for Design Research, Carnegie-Mellon's Software Engineering Institute, Xerox's PARC and Brunel's Organization and System Design Centre use the Design Research approach [10].

The figure below illustrates how Design Research is applied to the development of the PRM and PAM. 


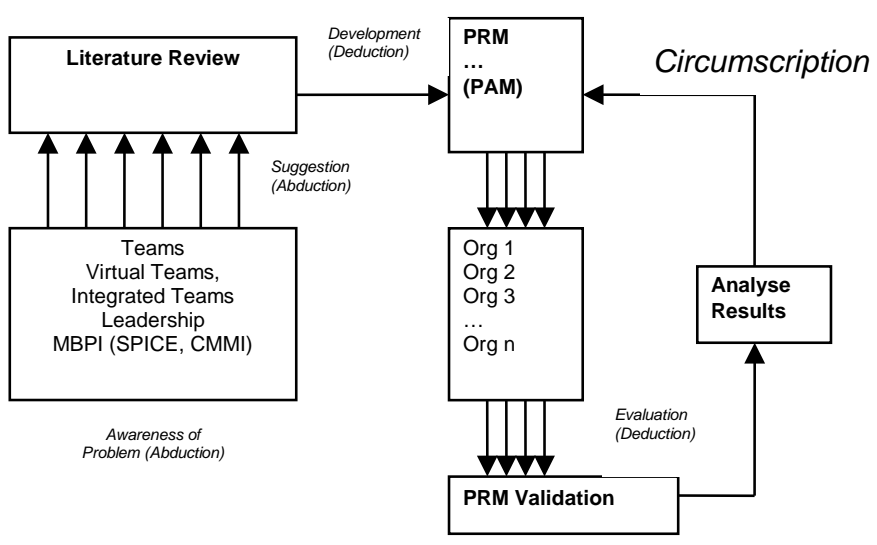

Figure 2: Using Design Research to develop PRM

\section{Model Architecture}

The Process Reference Model (PRM) has architecture with three layers. It comprises a foundational layer of generic leadership skills that are required in any situation requiring leadership, and a further two layers comprising leadership skills for integrated teams and virtual teams.

The figure below illustrates the model architecture.

Virtual Team Leadership Factors

Integrated Team Leadership Factors

Generic Leadership Factors

Figure 3: PRM Architecture; high-level functional view

Three factor groups contribute to effective integrated team leadership in a virtual environment:

1. Generic Leadership Skills. There is a generic set of leadership skills/qualities that will apply in both face-to-face and virtual team environments. This generic set is identified and distilled from the wealth of leadership research over time.

2. Specific examples of practices for integrated teams. The integrated teaming goals and practices of the literature constitute leadership criteria by default in the sense that someone has to give effect to them, and that will be the responsibility of the leader.

3. Specific Virtual Environment Challenges for Leaders. The virtual teaming challenges outlined by Bell \& Kozlowski will be met by an effective leader. These factors have been hypothesized by Bell \& 
Kozlowski [11] as being specific factors influencing the success of virtual team leaders.

Significantly, this architecture affords a degree of flexibility in how it is applied. When transformed into a Process Assessment Model it could be used to assess leadership capability of integrated teams operating in virtual environments.

This PRM architecture also theoretically allows for the assessment of virtual teams only, and of integrated teams only by using the generic leadership layer plus the relevant virtual or integrated factor layer.

This PRM architecture also could be useable to assess the generic leadership capability of a conventional co-located team that is neither virtual nor integrated.

An alternative way to view the PRM is from an environmental (in contrast to the functional) perspective. Leadership factors apply to the following five environments; Individual, Project, Organizational, Socio-cultural, and International. The environments are nested concentrically, as seen in the figure below.

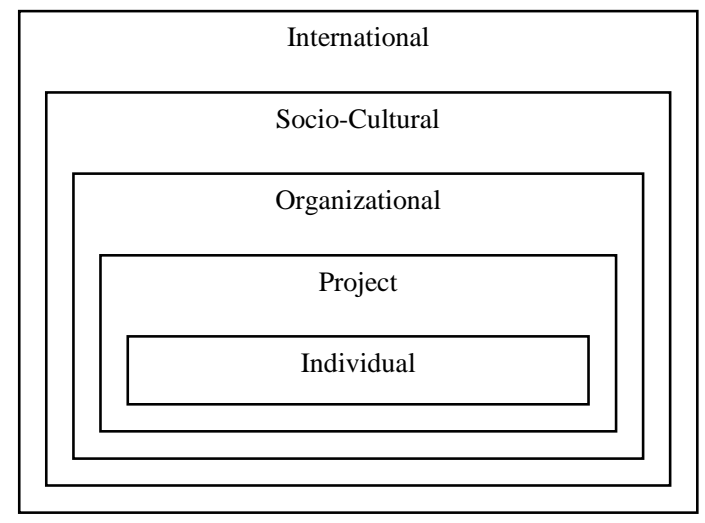

\section{Figure 4: PRM Architecture; environmental view}

Leadership factors from the PRM could be re-assigned from a functional level to an environmental level. This alternative view (analogous to the way in which the processes can be viewed from a staged or continuous perspective) may conceivably offer greater flexibility in how the PRM is understood and applied, though it must be stressed that doing so here is outside of the scope of this research project, and should be considered a strong possibility for future research.

\section{Model Content}

This paper focuses on the three level functional view of the model (Generic, Integrated and Virtual, as discussed in Section 4), leaving the environmental view for possible later treatment.

Each layer has a number of processes, each defined in terms of a purpose and set of outcomes. Future additions, through a PAM, include a list of possible base practices 
and input and output work-products, which provide objective evidence of performance.

An example of the first process "Create a Shared Vision" is shown below (example is shown in Arial font):

\section{Create a Shared Vision (sample process)}

Purpose: to perceive a guiding principle/idea that captures the imagination of members to create a shared vision and inspire them to realize that vision.

Outcomes: as a result of the successful implementation of creating a shared vision:

1. The leader perceives and formulates a unified vision of what is to be accomplished, ideally seen as an accomplished fact.

2. The leader develops a strong commitment to the achievement of that vision, based on a sense of rightness and timeliness, such that they have sufficient resilience to overcome goal frustrating events.

3. The leader develops a clear and unambiguous set of objectives or goals that are concrete and achievable.

The process might be further explained with the following:

Elaboration: the shared vision is a clear and unambiguous expression of an envisioned future. It is the basis for a common understanding among stakeholders of the aspirations and governing ideals of the team in the context of that desired outcome. It is conditional on being effectively communicated by the leader to the team; the shared vision grounds the team's governing ideas and principles and allows for appropriate objectives to be derived. Highly effective groups are often convinced they are engaged in important work, sometimes nothing short of being on a "mission from God". The work becomes an abiding obsession, a quest that goes well beyond mere employment. This intensely shared vision and sense of purpose endows cohesion and persistence.

The following tables list the processes:

\begin{tabular}{l}
\hline 1. Generic Leadership Personality Factors \\
\hline 1.1 Create a shared vision \\
\hline 1.2 Communicate shared vision to create optimism \\
\hline 1.3 Display integrity/good character and competence \\
\hline 1.4 Create trust \\
\hline 1.5 Action-oriented \\
\hline 1.6 Accepts responsibility \\
\hline 1.7 Individualized consideration \\
\hline 1.8 Original thinking \\
\hline 1.9 Resilience \\
\hline 1.10 Conceptual ability \\
\hline 1.11 Empathy \\
\hline 1.12 Judgment \\
\hline 1.13 Self-worth \& competence \\
\hline 1.14 Rewards desirable performance \\
\hline 1.15 Management-by-exception (passive) \\
\hline Table $\mathbf{1}:$ Generic Leadership Personality Factors \\
\hline 2. Integrated Team Leadership Factors \\
\hline 2.1 Establish the project's work environment \\
\hline 2.2 Establish the project's shared vision \\
\hline 2.3 Establish the integrated team structure \\
\hline
\end{tabular}




\begin{tabular}{ll}
\hline 2.4 Allocate requirements to integrated teams \\
\hline 2.5 Establish integrated teams \\
\hline 2.6 Ensure collaboration among interfacing teams \\
\hline 2.7 Establish empowerment mechanisms \\
\hline 2.8 Establish rules and guidelines for integrated teams \\
\hline 2.9 Balance team and home organization responsibilities \\
\hline
\end{tabular}

Table 2: Integrated Team Leadership Factors

\section{Virtual Team Leadership Factors}

3.1 Recruit required expertise for virtual team

3.2 Provide synchronous, information-rich channels of communication

\begin{tabular}{l} 
3.3 Devolve leadership functions to team \\
\hline 3.4 Perform complex tasks in real-time \\
\hline 3.5 Manage team boundaries \\
\hline 3.5 Establish and maintain stable team membership \\
\hline 3.7 Define roles and perform tasks synchronously \\
\hline 3.8 Establish performance management functions to compensate for temporal distribution \\
\hline 3.9 Establish team development practices in response to real-time requirement \\
\hline 3.10 Establish effective self-regulation functions across multiple boundaries
\end{tabular}

3.11 Establish unique team culture where team spans multiple boundaries

3.12 Establish operating procedures to allow members to regulate their own performance

3.13 Establish effective team development functions in discrete lifecycle projects

3.14 Manage role ambiguity and conflict where members hold multiple roles

3.15 Establish effective team development functions where members hold multiple roles

Table 3: Virtual Team Leadership Factors

\section{Preliminary Results}

The project plan for the development of the leadership model calls for between five and eight data collection iterations with organizations operating multi-disciplinary virtual teams. During these iterations a person or persons performing leadership/ management of virtual integrated teams is interviewed to determine the existence of objective evidence (in the form of artefacts or activities) that might validate the process reference model (PRM).

The rationale is that if the purpose/outcome statements of the PRM can be linked to work-products and activities then this will serve to validate the PRM and form the basis of a Process Assessment Model in keeping with ISO/IEC 15504-2:2004

At the time of writing, four data collection sessions have been performed. A high degree of consistency is observed in the raw data, which point to substantial elements being valid. It is too soon to draw further conclusions. The participant organizations are characterized as high-profile multi-national IT companies, both of whom routinely perform technology development projects involving integrated virtual teams. The 
managers interviewed expressed their approval of the leadership model in terms of its scope, content, aims, and approach. Each of these will be briefly discussed below.

The scope was considered to be comprehensive; it appears to cover all that needs to be covered. A preliminary finding suggests that in certain areas, the model could be simplified, with some consolidation of related processes.

The content was considered sufficiently detailed to give adequate understanding of the underlying ideas of the processes. Again, some simplification and consolidation of the content appears to be indicated.

The aims of the model were considered to be worthy in the sense that being an effective manager/leader of an integrated virtual team is recognized by the participants as challenging. The stakes can be high, careers sometimes depending on successful outcomes. A leadership model aimed at equipping project managers to be more effective is seen as a worthwhile undertaking.

Finally, the approach of the model that takes a practical stance and harmonizes with process assessment methods that the manager/leaders are already somewhat familiar with is considered to be a good approach. "Good" in this sense implies that the manager/leader can see how to apply it in a meaningful way using their existing skillsets and understanding.

Criticisms mainly concerned there being too much detail in some areas and redundant detail in others; this is an expected result of deliberately building in complexity to the first draft of the model with a view to simplifying it in light of feedback and data analysis. The rationale being that it is better to remove material as a result of refinement, than it is to add material, particularly when the additional material has not been subject to the full scrutiny of the interview participants.

An example of this apparent redundancy is seen in Generic Leadership factor 1.1 Create and communicate a shared vision, and in the Integrated Teams Leadership factor 2.2 Establish the project's shared vision. Shared vision appears repeatedly in the general literature on leadership. It also figures prominently in the integrated teaming literature in ways specific to integrated teams. It is arguably not appropriate to omit it from either set of factors. The final disposition is yet to be decided, requiring further data and consideration.

\section{Conclusion}

The goal of achieving synergy in group endeavours is a sometimes elusive one for IT development teams. This research has shown that the development of a process reference model for the purposes of assessing the capability of leadership processes appears to be valid.

The development of such a model has potential benefits for project managers and team leaders from a wide variety of backgrounds.

\section{References}


[1] Eisenhower, D. D. (1988) The Eisenhower Diaries. Edited by Robert H. Ferrell. New York: Norton

[2] Yukl, G., (1994). Leadership in Organisations. Englewood Cliffs, N.J. PrenticeHall.

[3] Bennis, W. and Nanus, B., (1985). Leaders: the strategies for taking charge. New York, Harper and Row.

[4] Bennis, W. (1994). On Becoming a Leader, What Leaders Read 1, Perseus Publishing, p 2

[5] Drucker, P. (1996), Managing in a Time of Great Change, Butterworth Heinemann, London.

[6] Takala, T., (1998). Plato on Leadership. Journal of Business Ethics 17: pp 785798.

[7] Repenning, N.P., Sterman, J.D., (1997) Getting Quality the Old-Fashioned Way: Self-Confirming Attributions in the Dynamics of Process Improvement. Sloan School of Management, MIT., Cambridge, MA. (Available at:

http://web.mit.edu/jsterman/www/SDG/Attrib.pdf )

[8] Humphrey, W.S., (2002). Winning with Software. Addison Wesley Longman, Reading Massachusetts

[9] Deming, W.E., (2000), Out of the Crisis, MIT Press, Cambridge MA.

[10] Vaishnavi, V. and Kuechler, W. (2004/5). “Design Research in Information Systems” January 20, 2004, last updated January 18, 2006. URL:

http://www.isworld.org/Researchdesign/drisISworld.htm Authors email: vvaishna@gsu.edu kuechler@unr.edu

[11] Bell, B.S., Kozlowski, S.W. (2002) A Typology of Virtual Teams: Implications for Effective Leadership. Group and Organisational Management, Vol. 27, No.1 p 1419. 